\title{
SOCIAL INFORMATION SYSTEMS: IMPACT ON THE MORTALITY RATE OF A PUBLIC HEALTH PROGRAM
}

\author{
Jeferson Gonçalves de Oliveira ${ }^{1}$, Cristiana Fernandes De Muylder ${ }^{1}$, \\ Fernando Hadad Zaidan ${ }^{2}$, Ana Maria Pereira Cardoso ${ }^{1}$ and José Nelio Januário ${ }^{3}$ \\ ${ }^{I}$ FUMEC University, Rua Cobre 200 - Belo Horizonte, $M G$ - Brazil \\ ${ }^{2}$ Technological Education Institute - R Tomé de Souza 1061 - Belo Horizonte, MG, Brazil \\ ${ }^{3}$ UFMG Federal University of Minas Gerais, 6627 Antônio Carlos Ave, Belo Horizonte, MG, Brazil
}

\begin{abstract}
Many recent studies have underscored the complexity of public health systems. At the same time, information systems are discussed from a strictly technological point of view to break away from a social context in which they are inseparable. Furthermore, the literature lacks research on the implementation of these systems in environments that target social innovation. To explore these relationships, this study seeks to answer the following question: What are the relationships/influences between the Social Information System, public health and social innovation? Thus, the purpose of this research is to develop an analysis model of the relationship between the studied constructs and apply it to the reality of the Neonatal Screening Program of the State of Minas Gerais (PTN-MG). To do so, the study was applied within the SUS, in the state of Minas Gerais, using the program's 15-year database. For testing the relationships between model constructs, statistical techniques of multivariate data analysis were employed. Key findings confirm that healthcare networks are configured as complex systems that require information systems with features that respect this concept. In addition, it is noted that the information system is a fundamental pillar in social innovation in health, as it has shown a significant relationship with the reduction of health problems and with the PTN-MG quality indicators. From this new tested model, others will emerge pointing to the scientific and social contribution of this research, organized in documents.
\end{abstract}

\section{KEYWORDS}

Social Information Systems, Complexity Theory, Public Health, Social Innovation 


\section{INTRODUCTION}

Health care is described in the literature as complex adaptive systems, where there is interdependence between the actors involved promoted by interconnectivity, that is, the action of an actor can broadly influence the other connected actors (Begun et al., 2003). Consequently, a system may be considered "complex" when the interdependencies, which define it, also make it very dynamic, alternating periods of stability and chaos.

Adhering to this complexity, the principle of integrality of SUS (Brazilian Medical Care Public System) makes it necessary to aggregate actions - including health promotion, disease prevention, treatment, and rehabilitation - to allow an integration between the different areas that influence the health of the individual (Ministério da Saúde, 2018). Thus, this specific health system has multidimensional characteristics due to its interaction with other sectors of society, which has a direct or indirect impact on the health-disease process, suffering and causing transformations in the context of the ethical, ecological, epidemiological, strategic, educational, transcendental, economic, political, and psycho-socio-cultural dimensions of the health sector (Chaves, 1998).

At the same time, health care has also been the focus of research by the Centre de Recherche sur les Innovations Sociales (CRISES) ${ }^{1}$ from the point of view of Social Innovation. Martinelli et al. (2003) show that social innovation, in its product and process dimensions, is characterized by at least three forms of achievement, alone or combined, carried out through some form of collective action: a) contributes to meeting human needs not considered or satisfied; b) increases access rights; c) increases human capabilities.

In the health context, social innovation is understood to be necessary to promote the development of new medicines, vaccines, and essential diagnoses, in addition to helping in public and private efforts to maintain essential services and promote health at the individual and community level (Gardner et al., 2007). As an example of this, in 2001 the Brazilian Ministry of Health - through the ordinance GM/MS No. 822 (Ministério da Saúde, 2001)- includes the National Neonatal Screening Program as a prominent public health policy for early detection of congenital diseases. This program is intended to cover $100 \%$ of live births in Brazil.

Neonatal screening is an early diagnostic strategy, which allows the detection of various diseases - metabolic, genetic and infectious - often with symptoms noticeable only through examination performed in the first days of the newborn's life. This early diagnosis research ensures medical intervention with the required urgency in children with certain diseases before the onset of irreversible sequelae (Núcleo de Ações e Pesquisa em Apoio Diagnóstico, 2018).

In Minas Gerais, the commonly known "foot test" is offered by the SUS to the entire state population through the Neonatal Screening Program (PNP-MG). The examinations and monitoring of newborns are done by the Center for Actions and Research in Diagnostic Support (Nupad), a complementary body of the Faculty of Medicine of the Public University of Minas Gerais (UFMG). Currently, nearly 6 million children have been detected by the programs and over 5,000 are being monitored (Núcleo de Ações e Pesquisa em Apoio Diagnóstico, 2018).

Given this scenario of complexity to provide social innovation, information technology (IT) should be discussed and utilized to meet the conditions of this environment. Thus, the scope of Social Information Systems (SISs) is broader, as it should support and foster the development

\footnotetext{
${ }^{1}$ Canadian interuniversity and multidisciplinary organization founded in 1986 and a pioneer in the studies of social innovation. It is formed by the Universities of Québec, Laval, Concordia, School of High Commercial Studies of Montreal and the National Institute of Scientific Research - Urbanization, Culture and Society.
} 
of social and collaborative skills over time. In addition, they should facilitate the provision of services (e.g., patient in the health system) and develop social skills inherent to these systems (Kuziemsky et al., 2016).

Thus, social information systems will play an important role in transforming health systems into collaborative patient-centered systems that support care throughout the flow of care, through collaborative networks that facilitate relationships and the integration of people and processes (Kuziemsky et al., 2016). In the present case, it appears that the health information system acquires the characteristics of a social information system.

Based on this conjuncture, we intend to understand the following research problem: What are the relationships/influences between the Social Information System (Social Information System), PTN-MG (Public Health) and Health Problems? Considering this scenario, the main goal of this study is to empirically test a model that evidences the role of the social information system in the process of social innovation in the health area.

This work has five sections: the first consists of the introduction to the theme; the second discusses the methodology; in the third, the results are presented; and finally, the article presents the final discussions and recommendations for future research.

\section{METHODOLOGY}

The research field of this study is the state of Minas Gerais, located in the southeast of the country and with an estimated population of more than 21,000,000 inhabitants (Instituto Brasileiro de Geografia e Estatística, 2017), where we sought to focus on the Neonatal Screening Program of Minas Gerais.

The network is currently composed of approximately 4,000 basic health units, 119 hospitals, 07 Blood Collection Center, more than 20,000 health professionals, a reference center, 52 family health units and has coverage in all 853 municipalities of the State (Núcleo de Ações e Pesquisa em Apoio Diagnóstico, 2018).

\subsection{Analytical Model, Hypotheses and Variables}

The model proposed in this article can be classified as exploratory and, from the literature review, Figure 1 is observed that illustrates the proposed research problem: What are the relationships/influences between the Health Information System (Social Information System), PTN-MG and health problems? 


\section{SOCIAL INFORMATION SYSTEMS: IMPACT ON THE MORTALITY RATE OF A PUBLIC}

HEALTH PROGRAM

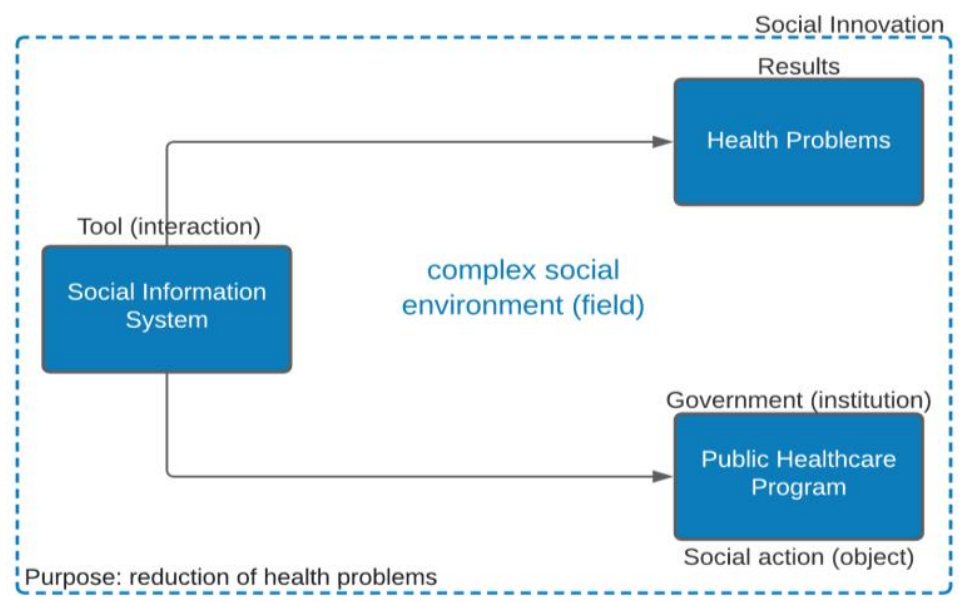

Figure 1. Model for evaluating the impact of SISs on IS and health problems Source: Developed by the authors

Thus, it is intended to quantitatively measure the result of Social Innovation in Health (Health Problems), during the challenges of complexity (Public Health), and to investigate the role of the SIS in this relationship. The considerations examined in this model are based on the literature presented in Table 1.

Table 1. List of authors that assert the model's factors

\begin{tabular}{|c|c|c|}
\hline Variable & Factors of the Social Information System & References \\
\hline SIS1 & $\begin{array}{l}\text { Number of users or nodes of IS access (systemic } \\
\text { and hologram principles of complexity) }\end{array}$ & $\begin{array}{l}\text { Aritua et al. (2008); Bar-Yam (1997); } \\
\text { Baranger (2000); Casti (1994); Cilliers (2000) }\end{array}$ \\
\hline SIS2 & $\begin{array}{l}\text { The amount recorded of daily interactions (systemic } \\
\text { and hologram principles of complexity) }\end{array}$ & $\begin{array}{l}\text { Aritua et al. (2008); Bar-Yam (1997); } \\
\text { Baranger (2000); Casti (1994); Cilliers (2000) }\end{array}$ \\
\hline SIS3 & $\begin{array}{l}\text { Number of feedback functions (retroactive, recursive } \\
\text { principles and autonomy/dependence on complexity) }\end{array}$ & $\begin{array}{l}\text { Aritua et al. (2008); Luhmann (1999); Wiener } \\
\text { (1950) }\end{array}$ \\
\hline SIS4 & $\begin{array}{l}\text { Number of feedback actions observed in the IS } \\
\text { (retroactive, recursive principles and } \\
\text { autonomy/dependence on complexity) }\end{array}$ & $\begin{array}{l}\text { Aritua et al. (2008); Luhmann (1999); Wiener } \\
\text { (1950) }\end{array}$ \\
\hline SIS5 & $\begin{array}{l}\text { Number of self-regulation adjustments in IS } \\
\text { resulting from feedback actions (retroactive, } \\
\text { recursive principles and autonomy/ dependence on } \\
\text { complexity) }\end{array}$ & $\begin{array}{l}\text { Aritua et al. (2008); Luhmann (1999); Wiener } \\
\text { (1950) }\end{array}$ \\
\hline PTN1 & Percentage of test collection on the optimum date & \multirow{5}{*}{ Ministério da Saúde (2018) } \\
\hline PTN2 & Age of newborn at first visit - hypothyroidism & \\
\hline PTN3 & Age of newborn at first visit - phenylketonuria & \\
\hline PTN4 & Age of newborn at first fibrosis consultation - cystic & \\
\hline PTN5 & Newborn age at first visit - sickle cell disease & \\
\hline AS1 & Overall death rate (mortality rate) & \multirow{5}{*}{$\begin{array}{l}\text { Grindell et al (2018); Hean et al. (2015). } \\
\text { Nuño-Solinís (2014); Schiavo et al. (2016); } \\
\text { Vechakul et al. (2015) }\end{array}$} \\
\hline AS2 & Hypothyroidism death rate (mortality rate) & \\
\hline AS3 & Phenylketonuria death rate (mortality rate) & \\
\hline AS4 & Sickle cell disease death rate (mortality rate) & \\
\hline AS5 & Cystic fibrosis death rate (mortality rate) & \\
\hline
\end{tabular}

Source: Prepared by the authors 
IADIS International Journal on WWW/Internet

The factors of the social information system were based on the principles of complexity theory, considering the social information system as part of a complex social system. For this, variables were thought that could indicate adherence to the principles: systemic, hologram, recursive, autonomy/dependence and retroactive.

The variables SIS3, SIS4 and SIS5 were obtained from the PTN-MG database and accounted for all the actions or feedback functions that the information system had in the period. Self-regulation was considered when the feedback action resulted in an adjustment in the PTN-MG - identified some need and generated automatic correction actions that were successful.

The variables SIS3, SIS4 and SIS5 were obtained from the PTN-MG database and accounted for all the actions or feedback functions that the information system had in the period. Self-regulation was considered when the feedback action resulted in an adjustment in the PTN-MG - identified some need and generated automatic correction actions that were successful.

Regarding the factors of the Neonatal Screening Program of the State of Minas Gerais, this study uses variables recommended by the Ministry of Health: coverage of the program, percentage of collections performed at the age considered ideal (up to the 5th day of life), the age of the newborn at the time of the first consultation (for those who presented altered tests in the screening) and the number of collection points for the test in the State. Thus, this construct does not measure the PTN-MG itself, but rather the variables considered fundamental by the Ministry of Health to evaluate the quality and efficiency of the Program.

On the other hand, the factors of Health Problems of the model are based on the metrics found in the literature, specifically for measuring the results of social innovation in health (Bazzano et al., 2017; Currie and Seddon, 2014; Grindell et al., 2018; Hean et al., 2015; Mummah et al., 2016; Nuño-Solinís, 2014; Schiavo et al., 2016; Singh, 2017; Vechakul et al. 2015). In addition, for the application of these concepts in PTN-MG, indicators were pointed out, based on the final objective of neonatal screening: "early diagnosis, in a timely manner, so that the necessary interventions allow the reduction of mortality and morbidity for congenital and hereditary diseases of the newborn" (Januário, 2015, p. 7).

The death rates used were related to children who had early outpatient follow-up in PTN-MG. Monthly accumulated rates were used since the beginning of the tests for each disease to analyze a longer period for the calculation (above 1 year). Thus, the accumulated monthly rate was calculated as follows for each of the diseases: (number of children who died/number of children under follow-up) x 100. All other variables were also calculated or accounted for month by month from January 2004 to April 2019.

Thus, this study considered program variables that could translate the impact and social transformation, in addition to clear results through the reduction of health problems in the children of the program. From the proposed model, we intend to test the following hypotheses (Figure 2): 


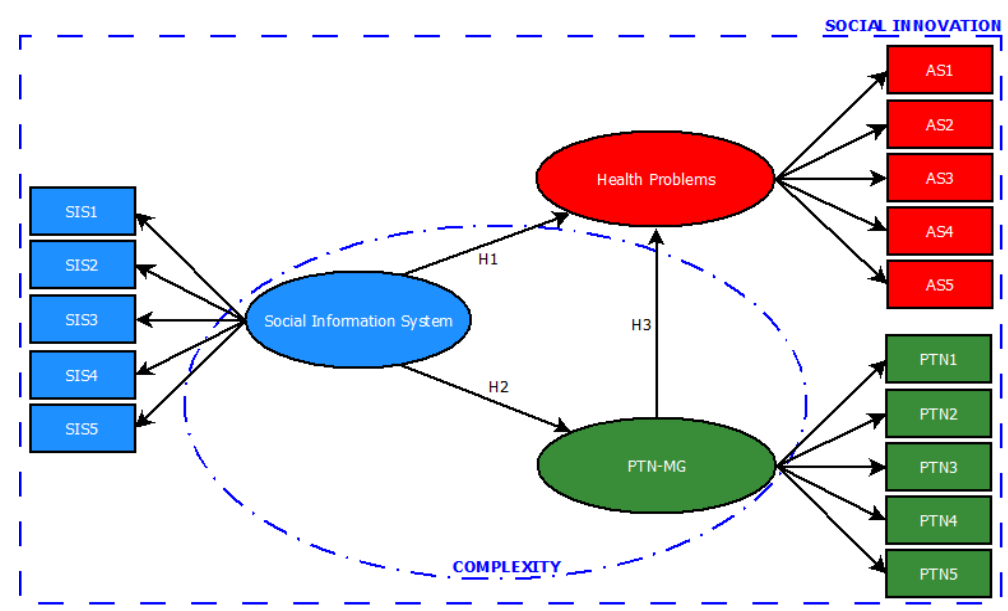

Figure 2. Hypotheses to be worked Source: Prepared by the authors

Thus, the hypotheses are described below:

- Hypothesis 1 (H1): The social information system influences health problems.

- Hypothesis 2 (H2): The social information system influences PTN-MG.

- Hypothesis 3 (H3): The social information system and the PTN-MG influence health problems.

In the proposed model, it is observed that social innovation (territory type) comprises all constructs. This is because they present themselves as an integral part of IS. For this, this work was based on the dimensions of analysis of The SI of Cloutier (2003) that considers the following items: object (PTN-MG), field (State of Minas Gerais), target (individuals), objective (reduction of health problems), process (multisectoral and interdisciplinary) and result (health problems metrics).

In addition, the Tardif and Harrison (2005) thesaurus represented by social transformation (Table 2) are also considered:

Table 2. Social innovation concepts used

\begin{tabular}{|l|l|l|l|l|}
\hline Social Transformation & Social Action & Proposal & Institution & Restriction \\
\hline Reconstruction & $\begin{array}{l}\text { Neonatal Screening } \\
\text { Program (Policies } \\
\text { and Programs) }\end{array}$ & $\begin{array}{l}\text { Reduction of Health } \\
\text { Problems (Common Good, } \\
\text { General interest) }\end{array}$ & Government & $\begin{array}{l}\text { Complexity } \\
\text { presented by } \\
\text { Public Health }\end{array}$ \\
\hline
\end{tabular}

Source: Prepared by the Author

Although the SIS is an integral part of the PTN-MG, we opted for separation to better understand its role in both the Program and health problems. In addition, it has been pointed out as one of the main characteristics of IS in health (De Rosa, 2017; Sliwa et al., 2017; Warnecke, 2017; Wass and Vimarlund, 2015). It is therefore intended to confirm this finding.

Therefore, the suggested model aims to measure relationships between constructs of the model and the possible influences exerted between them. For illustration purposes, the variables of each construct were represented by its abbreviated name and a sequence number (construct variable 01 "social information system" was named SIS1, and so on). 


\subsection{PTN-MG Database}

The database used to verify the proposed model was analyzed from 01/2004 to 04/2019, corresponding to approximately 15 years (equivalent to approximately 3,700,000 children screened). The source of these data will be the Center for Actions and Research in Diagnostic Support of the Faculty of Medicine of UFMG (Nupad), which is the reference center of PTN-MG in the state of Minas Gerais. The database is hosted on the Microsoft SQL Server Database Manager System (DbMS).

\subsection{Analysis and Interpretation of Data}

The statistical study for the validation of the proposed study was done through multivariate analysis. According to Hair et al. (2009), multivariate analysis refers to all statistical techniques that simultaneously analyze multiple measurements about individuals or research objects. One of the main objectives of these techniques is to expand the exploratory ability of the researcher and to deal with the interrelationships between variables simultaneously. Specifically, for this work, two of these techniques stand out: confirmatory factor analysis and structural equation modeling.

The set available for the analyses consists of 184 observations and 18 variables, 15 referring to the development of the constructs, one referring to the month, another to the year and a unique identifier of each observation. The data cover the period from January 2004 to April 2019. In the description of the variables, measures of central tendency, position and dispersion were used.

It was verified the existence of two types of outliers: univariate, which represent divergent responses based on each of the variables of the model, and the multivariate variables, which present a different response pattern considering all variables at the same time.

The univariate outliers were diagnosed by standardizing the results, so that the mean of the variable was 0 and the standard deviation 1 . Thus, univary outliers were considered those observations with standardized scores outside the range of [-3.29;3,29] (Hair et al., 2009).

Multivariate outliers were diagnosed based on Mahalanobis $\mathrm{d}^{2}$ measurement. According to Hair, et al. (2009) this measure verifies the position of each observation compared to the center of all observations in a set of variables, and at the end, a chi-square test is performed. Individuals with a measurement significance of less than 0.001 are considered multivariate outliers.

Regarding univariate normality, the Shapiro-Wilk normality test (Shapiro and Wilk, 1965) was used. The Henze-Zirkler's test (Henze and Zirkler, 1990) was used to verify the multivariate normality of the data.

Initially, to verify the linearity of the data, Spearman correlations (Hollander and Wolfe, 1999) of the variables were analyzed alongside, since a significant correlation coefficient at the level of $5 \%$ is indicative of the existence of linearity. Additionally, the Bartlett test (Mingoti, 2005) was performed to measure linearity in each construct.

Initially, to verify the linearity of the data, Spearman correlations (Hollander \& Wolfe, 1999) of the variables were analyzed alongside, since a significant correlation coefficient at the level of $5 \%$ is indicative of the existence of linearity. Additionally, the Bartlett test (Mingoti, 2005) was performed to measure linearity in each construct. 
To evaluate the relationships between the constructs, the structural equation model was used through the Partial Least Square (PLS) approach. PLS (Vinzi et al., 2010) was developed as an alternative to the traditional approach based on the covariance matrix (CBSEM), being a technique that offers greater flexibility in data modeling, since it is not necessary to satisfy some harsher assumptions such as multivariate data normality, independence between observations and high sample size.

The process of modeling, structural equations is divided into two parts: Measurement Model and Structural Model. To verify the validity of the measurement model, that is, the capacity of the set of indicators of each construct to accurately represent its respective concept, the dimensionality, reliability and convergent validity were evaluated. To verify convergent validity, the criterion proposed by Fornell and Larcker (Fornell and Larcker, 1981) was used, which indicates convergent validation when the Extracted Average Variance - AVE is greater than $50 \%$ (Henseler et al., 2009) or $40 \%$ in the case of exploratory research (Nunnally and Bernstein, 1994).

Cronbach's Alpha and Composite Reliability (Chin, 1998) were used to measure reliability. According to Tenenhaus et al. (2005) these indicators should be greater than 0.70 for an indication of construct reliability, and in exploratory research values above 0.60 are also accepted (Hair et al., 2009). For discriminant validity, the cross-loading method (Barclay et al., 1995) was used, which defines that discriminant validity is achieved when the factorial load of the item is greater than all its cross-factor loadings. To verify the dimensionality of the constructs, the Kaiser criterion (Kaiser, 1958) was used, which returns the amount of construct dimensions.

The Bootstrap method was used to calculate the confidence intervals for the weights of the measurement model and the coefficients of the structural model, providing information on the variability of the estimated parameters, thus providing the validation of the results. The Bootstrap method (Efron and Tibshirani, 1993) is widely used in inferences when the probability distribution of the variable of interest is not known.

$\mathrm{R}^{2}$ and GoF (Tenenhaus et al., 2005) were used to evaluate the quality of the adjustments. $\mathrm{R}^{2}$ represents on a scale of $0 \%$ to $100 \%$ how much independent constructs explain dependents, and in general, values lower than $25 \%$ represent weak explanatory capacity, values between $25 \%$ and $50 \%$ indicate moderate explanatory capacity and values above $50 \%$ show a substantial explanatory capacity (Hair et al., 2009). The GoF is a geometric mean of the AVE's of the constructs and $\mathrm{R}^{2}$ of the model and ranges from $0 \%$ to $100 \%$. The GoF in PLS, does not have the ability to discriminate valid models of invalids, besides not applying for models with formative constructs (Henseler and Sarstedt, 2012), only allows a synthesis of the Ave's and the $\mathrm{R}^{2}$ of the model in a single statistic, and may be useful for future adhesion scans of different samples to the model. The software used for the development of the analyses was $\mathrm{R}$ (version 3.6.0).

\section{RESULTS}

This work made an analysis of the outliers, which are observations that present a different response pattern from the other ones. We can sort, according to Hair et al. (2009), four types of outliers: a) data tabulation errors or coding failures; b) observations arising from an extraordinary event; c) extraordinary observations for which the researcher does not have an 
explanation; and d) observations that are in the usual range of values for each variable but are unique in their combination of values between variables. Univariate outliers consist of divergent responses based on each of the model variables, and the multivariate ones represent a different response pattern considering all variables at the same time.

As already explained in the methodology chapter, the univariate outliers were diagnosed by standardizing the results, so that the mean of the variable was 0 and the standard deviation 1. Thus, observations with standardized scores outside the range of $[-3.29 ; 3.29]$ were considered outliers (Hair et al., 2009). Based on this criterion, only 9 (0.33\%) observations considered atypical in a univariate way.

Multivariate outliers were diagnosed based on Mahalanobis $\mathrm{d}^{2}$ measurement. According to this criterion, no multivariate atypical observations were found.

However, it is believed that the observations are valid cases of the population, and their elimination could limit the generality of the multivariate analysis, although possibly improving its results (Hair et al., 2009). Thus, we chose not to exclude any of the cases.

\subsection{Normality and Linearity}

The Henze-Zirkler's test was used to analyze the multivariate normality of the data set. As a result, it was observed that the p-value found was less than 0.05 , indicating that there is no multivariate normality. The Shapiro-Wilk test was used to verify univariate normality, and only the PTN5 variations presented normal distribution.

However, the PLS (Partial Least Square) approach (Vinzi et al., 2010) was developed as an alternative to the traditional approach based on the covariance matrix (CBSEM), being a technique that offers greater flexibility in data modeling. In it, it is not necessary to satisfy some harsher assumptions, such as multivariate data normality, independence between observations and high sample size. Thus, the lack of normality of the data is no longer a major problem when working with structural equations.

Regarding the linearity of the data, initially the correlations of the variables were analyzed evenly since a significant correlation coefficient at the level of 5\% is indicative of the existence of linearity. Through spearman's correlation matrix (Hollander et al., 1999), it is observed that $88.57 \%$ of the relationships were significant at the level of 5\%.

In addition, the Bartlett test (Mingoti, 2007) was performed to verify the linearity in each construct. In all constructs, p-values lower than 0.05 were observed, indicating that there is significant evidence of linearity.

\subsection{Outer Model}

In the analysis of the measurement model, convergent validity, discriminant validity and construct reliability were verified. Convergent validity ensures that the indicators of a construct are correlated enough to measure the latent concept. Discriminant validity verifies whether constructs effectively measure different aspects of the phenomenon of interest. Reliability reveals the consistency of measurements in measuring the concept they intend to measure.

Dimensionality, reliability, and convergent validity were verified in the analysis of the quality and validity of the constructs. To verify the convergent validity, the criterion proposed by Fornell and Larcker (1981), which indicates convergent validation when the Average Extracted Variance - AVE is greater than 50\% (Henseler et al., 2009) or 40\% in the case of 
exploratory research (Nunnaly et al., 1994). Cronbach's Alpha (A.C. and Composite Reliability C.C.) (Chin, 1998).

Table 3 presents the weights, factor loadings and commonalities of the initial measurement model. Thus, it is possible to:

- PTN3 (Age of the newborn at the first visit - phenylketonuria) presented factorial load less than 0.5 and non-significant weight indicating that this item is not important in the formation of the construct.

- PTN1 initially presented negative weight, so to facilitate the analyses, this variable was inverted, so that PTN1-I represents the percentage of test collection outside the ideal date.

Table 3. Initial measurement model

\begin{tabular}{lccccc}
\hline Construct & Item & Weight & I.C. $-95 \%^{1}$ & C.F. $^{2}$ & Com. $^{3}$ \\
\hline & SIS1 & 0,17 & {$[0,15 ; 0,18]$} & 0,79 & 0,63 \\
& SIS2 & 0,22 & {$[0,21 ; 0,23]$} & 0,98 & 0,96 \\
Social Information System & SIS3 & 0,23 & {$[0,22 ; 0,24]$} & 0,98 & 0,96 \\
& SIS4 & 0,22 & {$[0,22 ; 0,23]$} & 0,98 & 0,97 \\
& SIS5 & 0,22 & {$[0,21 ; 0,23]$} & 0,97 & 0,94 \\
\hline & PTN1-I & 0,51 & {$[0,44 ; 0,60]$} & 0,86 & 0,74 \\
& PTN2 & 0,26 & {$[0,18 ; 0,33]$} & 0,69 & 0,48 \\
Neonatal Screening Program & PTN3 & 0,05 & {$[-0,07 ; 0,18]$} & 0,23 & 0,06 \\
& PTN4 & 0,20 & {$[0,10 ; 0,28]$} & 0,59 & 0,35 \\
& PTN5 & 0,35 & {$[0,28 ; 0,41]$} & 0,71 & 0,51 \\
\hline & AS1 & 0,28 & {$[0,26 ; 0,30]$} & 0,99 & 0,97 \\
& AS2 & 0,27 & {$[0,25 ; 0,29]$} & 0,96 & 0,93 \\
& AS3 & 0,16 & {$[0,14 ; 0,18]$} & 0,78 & 0,61 \\
Health Problems & AS4 & 0,28 & {$[0,26 ; 0,30]$} & 0,98 & 0,96 \\
& AS5 & 0,10 & {$[0,05 ; 0,15]$} & 0,58 & 0,34 \\
\hline${ }^{1}$ Bootstrap Range; ${ }^{2}$ Factor loading; ${ }^{3}$ Commonality. & & \\
\hline \multicolumn{7}{c}{}
\end{tabular}

Source: Prepared by the Author

Table 4 presents the weights, factor loadings and commonalities of the final measurement model, obtained after the removal of PTN3. Thus, it is possible to: 
IADIS International Journal on WWW/Internet

Table 4. Final measurement model

\begin{tabular}{lccccc}
\hline Construct & Item & Weight & I.C. - 95\% & C.F. & Com. $^{3}$ \\
\hline & SIS1 & 0,17 & {$[0,15 ; 0,18]$} & 0,79 & 0,63 \\
& SIS2 & 0,22 & {$[0,21 ; 0,22]$} & 0,98 & 0,96 \\
Social Information System & SIS3 & 0,23 & {$[0,22 ; 0,24]$} & 0,98 & 0,96 \\
& SIS4 & 0,22 & {$[0,22 ; 0,23]$} & 0,98 & 0,97 \\
& SIS5 & 0,22 & {$[0,21 ; 0,23]$} & 0,97 & 0,94 \\
\hline & PTN1-I & 0,51 & {$[0,44 ; 0,61]$} & 0,86 & 0,75 \\
Neonatal Screening Program & PTN2 & 0,27 & {$[0,18 ; 0,34]$} & 0,69 & 0,48 \\
& PTN4 & 0,20 & {$[0,11 ; 0,28]$} & 0,60 & 0,36 \\
& PTN5 & 0,35 & {$[0,29 ; 0,42]$} & 0,71 & 0,50 \\
\hline \multirow{5}{*}{ Health Problems } & AS1 & 0,28 & {$[0,26 ; 0,30]$} & 0,99 & 0,97 \\
& AS2 & 0,27 & {$[0,25 ; 0,29]$} & 0,96 & 0,93 \\
& AS3 & 0,16 & {$[0,14 ; 0,18]$} & 0,78 & 0,61 \\
& AS4 & 0,28 & {$[0,26 ; 0,30]$} & 0,98 & 0,96 \\
& AS5 & 0,10 & {$[0,05 ; 0,15]$} & 0,58 & 0,34 \\
\hline \multicolumn{5}{c}{ Bootstrap Range; ${ }^{2}$ Factor loading; ${ }^{3}$ Commonality. } & \\
\hline
\end{tabular}

Source: Prepared by the Author

Table 5 presents the analysis of convergent validity, dimensionality, and reliability of the constructs of the measurement model. Thus, it is possible to:

- In all constructs, reliability indices C.A. and C.R. were higher than 0.60 , thus evidencing their reliability.

- According to the Kaiser criterion, all constructs were one-dimensional.

- The AVE's of all constructs were higher than 0.40, thus evidencing the convergent validation of the same.

Table 5. Validation of measurement model

\begin{tabular}{lccccc}
\hline Constructs & Item & C.A. $^{1}$ & C.R. $^{2}$ & Dim. $^{3}$ & AVE $^{4}$ \\
\hline Social Information System & 5 & 0,97 & 0,98 & 1 & 0,89 \\
Newborn Screening Program & 4 & 0,70 & 0,82 & 1 & 0,52 \\
Health problems & 5 & 0,92 & 0,94 & 1 & 0,76 \\
\hline${ }^{1}$ Cronbach Alfa, ${ }^{2}$ Composite Reliability, ${ }^{3}$ Dimensionality, ${ }^{4}$ Extracted Variance. \\
\hline
\end{tabular}

Source: Prepared by the Author

Table 6 presents the discriminant validation by the method of crossed factorial loads (Barclay et al., 1995). It is observed that there was discriminant validation in all constructs since the factorial loads of the items were higher than their respective crossed factorial loads. 
SOCIAL INFORMATION SYSTEMS: IMPACT ON THE MORTALITY RATE OF A PUBLIC

HEALTH PROGRAM

Table 6. Discriminant validation by the method of crossed factorial loads

\begin{tabular}{lcccc}
\hline Construct & Item & $\begin{array}{c}\text { Social Information } \\
\text { System }\end{array}$ & $\begin{array}{c}\text { Neonatal Screening } \\
\text { Program }\end{array}$ & $\begin{array}{c}\text { Health } \\
\text { Problems }\end{array}$ \\
\hline \multirow{3}{*}{ Social Information System } & SIS1 & 0,79 & $-0,40$ & $-0,67$ \\
& SIS2 & 0,98 & $-0,53$ & $-0,88$ \\
& SIS3 & 0,98 & $-0,60$ & $-0,91$ \\
& SIS4 & 0,98 & $-0,57$ & $-0,86$ \\
\hline \multirow{3}{*}{ Neonatal Screening Program } & SIS5 & 0,97 & $-0,57$ & 0,69 \\
& PTN1-I & $-0,55$ & 0,86 & 0,35 \\
& PTN2 & $-0,29$ & 0,69 & 0,25 \\
Health Problems & PTN4 & $-0,25$ & 0,60 & 0,41 \\
\hline & PTN5 & $-0,44$ & 0,71 & 0,99 \\
& AS1 & $-0,93$ & 0,68 & 0,96 \\
& AS2 & $-0,88$ & 0,66 & 0,78 \\
& AS3 & $-0,57$ & 0,35 & 0,98 \\
& AS4 & $-0,92$ & 0,71 & 0,58 \\
\hline
\end{tabular}

Source: Prepared by the Author

Thus, it is evident that all three constructs are uniquely different from the others.

\subsection{Inner Model}

The measurement and regression models were performed using the PLS method. This has been referred to as a soft modeling technique with minimal demand, when considering the scales of measurements, sample size and residual distributions (Monecke and Leisch, 2012).

Table 7 presents the structural model. Thus, it is possible to:

- There was a significant influence ( $\mathrm{p}$-value $=0.00)$ and negative $(\beta=-0.57[-0.64 ;-0.51])$ of social information system on the Neonatal Screening Program, so the higher the Social Information System, the smaller the indicator of Neonatal Screening Program will tend to be.

- There was a significant influence $(\mathrm{p}-\mathrm{value}=0.00)$ and negative $(\beta=-0.77[-0.82 ;-0.71])$ of social information system on health problems, so the higher the Social Information System, the smaller health problems will tend to be.

- There was a significant influence ( $p$-value $=0.00)$ and positive $(\beta=0.20[0.15 ; 0.27])$ of the Neonatal Screening Program on Health Problems, so the higher the Neonatal Screening Program, the greater the health problems will tend to be.

- The Construct of Social Information System was able to explain $32.23 \%$ of the variability of the Neonatal Screening Program and both were able to explain $82.08 \%$ of the variability of Health Problems. In addition, it is worth mentioning that the model presented a GoF of $65.01 \%$. 
IADIS International Journal on WWW/Internet

Table 7. Structural Model

\begin{tabular}{l|l|c|c|c|c|c}
\hline \multicolumn{1}{c|}{ Endogenous } & \multicolumn{1}{c|}{ Exogenous } & $\beta$ & E.P. $(\beta)^{1}$ & I.C. $-95 \%^{2}$ & Valor-p & $\mathrm{R}^{2}$ \\
\hline $\begin{array}{l}\text { Neonatal Newborn } \\
\text { Screening Program }\end{array}$ & $\begin{array}{l}\text { Social Information } \\
\text { System }\end{array}$ & $-0,57$ & 0,06 & {$[-0,64 ;-0,51]$} & 0,00 & $32,23 \%$ \\
\hline \multirow{3}{*}{ Health Problem } & $\begin{array}{l}\text { Social Information } \\
\text { System }\end{array}$ & $-0,77$ & 0,04 & {$[-0,82 ;-0,71]$} & 0,00 & $82,08 \%$ \\
\cline { 2 - 7 } & $\begin{array}{l}\text { Neonatal Screening } \\
\text { Program }\end{array}$ & 0,20 & 0,04 & {$[0,15 ; 0,27]$} & 0,00 & \\
\hline
\end{tabular}

${ }^{1}$ Standard Error; ${ }^{2}$ Bootstrap range; $\mathrm{GoF}=65.01 \%$.

Source: Prepared by the Author

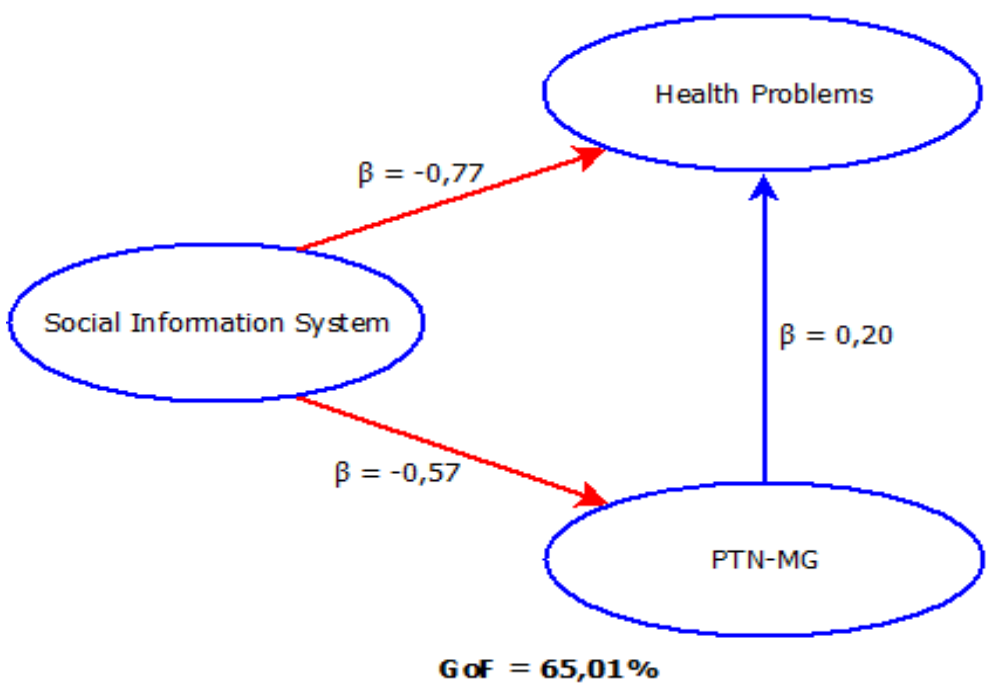

Figure 3. Structural Model Illustration

Source: Prepared by the Author

It is important to point out that the value $\beta$ shows the strength of relationships. This means that the closer to 1 , the greater the influence. The Social Information System had a $\beta=-0.77$ on health problems and was the largest $\beta$ the model. Thus, it represents an influence 3.85 times greater than the indicators of PTN-MG $(\beta=0.20)$ on health problems.

Thus, of the $82.08 \%$ observed in R2 of the model, it can be affirmed that the Social Information System represents approximately $65.16 \%$ of the total variability of health problems. PTN-MG represents $16.92 \%$ since it has a 3.85 times lower influence. 


\section{CONCLUSION}

Recently, several studies on social innovation have been carried out, however, the literature shows the complexity about this concept (Edwards-Schachter and Wallace, 2015). There are difficulties in the elaboration of indicators that allow to explain empirical phenomena related to the theme (Castro-Spila and Unceta, 2015; Unceta et al., 2016).

It is in this context that the model proposed in this study tries to explain the influence of the information system in a large public health program and, specifically, in the results that this program as a social innovation must achieve.

The results show that PTN-MG is a public health program that is configured as a social innovation, as it managed to solve the problems it proposes, that is, it reduced the mortality rate of the patients involved. The model showed that the reduction in the program's indicators has a significant relationship with the reduction of health problems over 15 years. In addition, considering that the SISO is part of the PTN-MG, $82 \%$ of the reduction observed in health problems can be explained by the program.

It is also noticed that the indicators recommended by the Ministry of Health to assess the quality of programs in the country may be insufficient. This is due to the strength of the indicators' relationship to health problems below the strength observed by the information system (3.5 times less). It is concluded, therefore, that the management of the program is a primary factor to be considered by federal policies regarding neonatal screening. The indicators pointed out by the government represent only part of the measurement.

Another important detail was the significant and negative relationship of the information system with both PTN-MG and health problems, that is, the higher the SISO, the lower the indicators and mortality. This is a valuable contribution, given the weight observed in the relationships between the constructs, as it reinforces that the complex characteristics must be considered when implementing a SISO.

Therefore, as a contribution, it can be emphasized that the results indicate that some factors must be considered in the planning and implementation of health information systems. These data are important so that initiatives, especially social innovation, can have indicators or clear metrics to demonstrate their effectiveness, especially in public policy actions.

As work limitations, it is understood that this study had its research carried out based on a specific health information system in operation in a Brazilian state. As a proposal for future research, the following can be indicated: application of the model in other realities and in other information systems to confirm the relationships identified.

\section{REFERENCES}

Aritua, B. et al., 2008. Construction client multi-projects: A complex adaptive systems perspective. International Journal of Project Management, Vol. 27, No. 1, pp. 72-79. https://doi.org/10.1016/ j.ijproman.2008.02.005.

Aritua, B. et al., 2008. Construction client multi-projects: A complex adaptive systems perspective. International Journal of Project Management, Vol. 27, No. 1, pp. 72-79. https://doi.org/10.1016/ j.ijproman.2008.02.005.

Baranger, M., 2000. Chaos, complexity, and entropy. New England Complex Systems Institute, Cambridge, USA. 
IADIS International Journal on WWW/Internet

Barclay, D. et al, 1995. The partial least squares (PLS) approach to casual modeling: personal computer adoption and use as an illustration. Technology Studies, Vol. 2, No. 2, pp. 285-309.

Bar-Yam, Y., 1997. Dynamics of complex systems, Addison-Wesley, Reading, MA, USA.

Bazzano, A. N. et al, 2017. Human-centred design in global health: A scoping review of applications and contexts. PloS one, Vol. 12, No. 11, pp. e0186744. https://doi.org/10.1371/journal.pone.0186744.

Begun, J. W. et al, 2003. Health Care Organizations as complex adaptive systems. In: S. S. Mick and M. E. Wyttenbach (Eds.), Advances in Health Care Organization Theory. Jossey-Bass, San Francisco, California, USA.

Casti, J. L., 1994. Complexification: explaining a paradoxical world through the science of surprise. Harper Collins, New York, USA.

Castro-Spila, J. and Unceta, A., 2015. Modes d'innovation sociale et gouvernance. Proceedings of the 4ème Colloque international de CRISES. Montréal, Canadá. Available in: https://crises.uqam.ca/wpcontent/uploads/2018/10/4D_Castro_Unceta.pdf.

Chaves, M., 1998. Complexidade e transdisciplinaridade: uma abordagem multidimensional do setor saúde. Revista Brasileira de Educação Médica, Vol. 22, No. 1, pp. 7-18. https://doi.org/10.1590/ 19815271v22.1-002. Available in: https://www.scielo.br/j/rbem/a/bSNRh7Lvjvd3K8TjxTMV6wF/? lang $=$ pt $\&$ format $=$ pdf.

Chin, W. W., 1998. The partial least squares approach to structural equation modeling. In G. A. Marcoulides (Ed.). Modern methods for business research. Lawrence Erlbaum Associates Publishers, Mahwah, NJ, USA. pp. 295-336.

Cilliers, P. (2000). What can we learn from a theory of complexity? Emergence, Vol. 2, No. 1, pp. 23-33. https://doi.org/10.1207/S15327000EM0201_03.

Cloutier, J., 2003. Qu'est-ce que l'innovation sociale?, Centre de Recherche sur les Innovations Sociales, Montréal, Canadá.

Currie, W. L. and Seddon, J. J., 2014. Social innovation in public health: can mobile technology make a difference? Information Systems Management, Vol. 31, No. 3, pp. 187-199. https://doi.org/10.1080/ 10580530.2014 .923263$.

De Rosa, E., 2017. Social innovation and ICT in social services: European experiences compared. Innovation: The European Journal of Social Science Research, Vol. 30, No. 4, pp. 421-432. https:// doi.org/10.1080/13511610.2017.1348936

Edwards-Schachter, M. and Wallace, M. L., 2017. Shaken, but not stirred: Sixty years of defining social innovation. Technological Forecasting and Social Change, Vol. 119, pp. 64-79. https://doi.org/10. 1016/j.techfore.2017.03.012.

Efron, B. and Tibshirani, R. J., 1993. An introduction to the bootstrap. Chapman \& Hall. New York, NY, USA.

Fornell, C. and Larcker, D. F., 1981. Evaluating structural equation models with unobservable variables and measurement error. Journal of Marketing Research, Vol. 18, No. 1, pp. 39-50. https://doi.org/10. $1177 / 002224378101800104$

Gardner, C. A. Et al., 2007. Technological and social innovation: a unifying new paradigm for global health. Health Affairs, Vol. 26, No. 4, pp. 1052-1061. https://doi.org/10.1377/hlthaff.26.4.1052.

Grindell, C. et al, 2018. Exploring the acceptability and usability of a novel social innovation to encourage physical activity: The iStep prototype. Health \& Social Care in the Community. Vol. 27. No. 2, pp. 383-391. https://doi.org/10.1111/hsc.12656.

Hair, J. F., et al, 2009. Multivariate data analysis: a global perspective. Prentice Hall, Upper Saddle River, NJ, USA.

Hean, S. et al, 2015. Using social innovation as a theoretical framework to guide future thinking on facilitating collaboration between mental health and criminal justice services. International Journal of Forensic Mental Health, Vol. 14, No. 4, pp. 280-289. https://doi.org/10.1080/14999013.2015. 1115445. 


\section{SOCIAL INFORMATION SYSTEMS: IMPACT ON THE MORTALITY RATE OF A PUBLIC}

HEALTH PROGRAM

Henseler, J. et al., 2009. The use of partial least squares path modeling in international marketing. In: Sinkovics, R. R. and Ghauri, P. N. (Ed.). New challenges to international marketing. Emerald Group Publishing Limited, Bingley, England. pp. 277-319. https://doi.org/10.1108/S1474-7979(2009) 0000020014

Henseler, J. and Sarstedt, M., 2013. Goodness-of-fit indices for partial least squares path modeling. Computational Statistics, Vol. 28, No. 2, pp. 565-580.

Henze, N., and Zirkler, B., 1990. A class of invariant consistent tests for multivariate normality. Communications in Statistics-Theory and Methods, Vol. 19, No. 10, pp. 3595-3617.

Hollander, M. and Wolfe, D., 1999. Nonparametric Statistical Methods. John Wiley \& Sons, New York, NY, USA.

Instituto Brasileiro de Geografia e Estatística, 2017. Estimativas da população residente no Brasil e unidades da federação com data de referência em $1^{\circ}$ de julho de 2017. IBGE, Rio de Janeiro, RJ, Brasil. Available in: ftp://ftp.ibge.gov.br/Estimativas_de_Populacao/Estimativas_2017/estimativa_ dou_2017.pdf.

Januário, J. N., 2015. Triagem neonatal em Minas Gerais: análise do contexto histórico e políticoinstitucional com enfoque nas estratégias empregadas e resultados alcançados. Universidade Federal de Minas Gerais, Belo Horizonte, MG, Brasil.

Kaiser, H. F., 1958. The varimax criterion for analytic rotation in factor analysis. Psychometrika, Vol. 23, No. 3, pp. 187-200. https://doi.org/10.1007/BF02289233.

Kuziemsky et al, 2016. A connectivity framework for social information systems design in healthcare. Proceedings AMIA Annual Symposium. pp. 734-742.

Luhmann, N., 1999. Zweckbegriff und Systemrationalität. Suhrkamp, Frankfurt am Main, Germany.

Martinelli F. et al, 2003. Social innovation, governance and community building. Scientific Periodic Progress Report Month, Vol. 18. Available in: hhtp://users.skynet.br/bk368453/singocom/index2. html.

Mingoti, S., 2005. Análise de dados através de métodos de estatística multivariada. Universidade Federal de Minas Gerais, Belo Horizonte, MG, Brasil

Ministério da Saúde (Brasil). 2018. Sistema Único de Saúde. Ministério da Saúde, Brasília, DF, Brasil. Available in: https://www.saude.mg.gov.br/sus.

Ministério da Saúde (Brasil). 2001. Portaria GM/MS no 822, de 6 de junho de 2001. Cria o Programa Nacional de Triagem Beonatal. Available in: https://bvsms.saude.gov.br/bvs/saudelegis/gm/2001/ prt0822_06_06_2001.html.

Monecke, A. and Leisch, F., 2012. semPLS: structural equation modeling using partial least squares. Journal of Statistical Software, Vol. 48, No. 3. Pp. 1-32. Available in: https://www.jstatsoft.org/ index.php/jss/article/view/v048i03/v48i03.pdf.

Mummah, S. A. et al, 2016. IDEAS (Integrate, Design, Assess, and Share): a framework and toolkit of strategies for the development of more effective digital interventions to change health behavior. Journal of Medical Internet Research, Vol. 18, No. 12, pp. e317. https://doi.org/10.2196/jmir.5927.

Núcleo de Ações e Pesquisa em Apoio Diagnóstico, 2018. NUPAD em números. NUPAD, Belo Horizonte, MG, Brasil. Available in: https://www.nupad.medicina.ufmg.br/nupad-em-numeros.

Nunnally, J. C. and Bernstein, I. H., 1994. Psychometric theory (3rd ed.). McGraw-Hill, New York, NY, USA.

Nuño-Solinís, R., 2014. Social and organizational innovation to tackle the challenge of integrated care of the chronically ill. Enfermeria Clinica, Vol. 24, No. 1, pp. 18-22. https://doi.org/10.1016/j.enfcli. 2013.08.007.

Schiavo, R. et al, 2016. Building community-campus partnerships to prevent infant mortality: Lessons learned from building capacity in four US cities. Journal of Health Disparities Research and Practice, Vol. 9, No. 3, pp. 80-93. 
IADIS International Journal on WWW/Internet

Shapiro, S. S. and Wilk, M. B., 1965. An analysis of variance test for normality (complete samples). Biometrika, Vol. 52, No. 3/4, pp. 591-611. https://doi.org/10.2307/2333709.

Singh, S., 2017. Gendered Bop Hygiene Markets in Rural India: A Case Study of Social Entrepreneurship and Social Innovation. The Hong Kong Journal of Social Work, Vol. 51, No. 01n02, pp. 51-72. https://dx.doi.org/10.1142/S0219246217000055.

Sliwa, S. I. et al, 2017. E-health, health systems and social innovation: a cross-national study of telecare diffusion. International Journal of Foresight and Innovation Policy, Vol. 12, No. 4, pp. 171-197. https://dx.doi.org/10.1504/IJFIP.2017.087082.

Tardif, C. and Harrisson, D., 2005. Complémentarité, convergence et transversalité: la conceptualisation de l'innovation sociale au CRISES. Centre de Recherche sur les Innovations Sociales, Montréal, Canadá. Available in: https://crises.uqam.ca/wp-content/uploads/2018/10/ET0513.pdf.

Tenenhaus, M. et al, 2005. PLS path modeling. Computational Statistics \& Data Analysis, Vol. 48, No. 1, pp. 159-205. https://doi.org/10.1016/j.csda.2004.03.005

Unceta, A. et al, 2016. Social innovation indicators. Innovation. The European Journal of Social Science Research, Vol. 29, No. 2, pp. 192-204. https://doi.org/10.1080/13511610.2015.1127137.

Vechakul, J. et al, 2015. Human-centered design as an approach for place-based innovation in public health: a case study from Oakland, California. Maternal and Child Health Journal, Vol. 19, No. 12, pp. 2552-2559. http://doi.org/10.1007/s10995-015-1787-x.

Vinzi, E. et al, 2010. Handbook of partial least squares. Springer, Berlin, Germany.

Warnecke, T., 2017. Social innovation, gender, and technology: bridging the resource gap. Journal of Economic Issues, Vol. 51, No. 2, pp. 305-314. http://dx.doi.org/10.1080/00213624.2017.1320508.

Wass, S. and Vimarlund, V., 2015. Challenges of stimulating a market for social innovation: provision of a national health account. Studies in Health Technology and Informatics, Vol. 210, pp. 546-550. http://dx.doi.org/10.3233/978-1-61499-512-8-546

Wiener, N., 1950. Cybernetics. Bulletin of the American Academy of Arts and Sciences, Vol. 3, No. 7 , pp. 2-4. https://dx.doi.org/10.2307/3822945. 